\title{
A geographical comparison of Assurance on Integrated Reporting
}

\author{
Maria Albertina Barreiro Rodrigues \\ Universidade Europeia - Laureate International Universities \\ ISCAL - Instituto Superior de Contabilidade e \\ Administração de Lisboa \\ Lisboa, Portugal \\ maria.rodrigues@universidadeeuropeia.pt
}

\author{
Ana Isabel Morais \\ Advance/CSG, ISEG - Lisbon School of Economics \& \\ Management, Universidade de Lisboa \\ Lisboa, Portugal \\ anamorais@iseg.utl.pt
}

\begin{abstract}
This paper explores the report of the companies. The focus is on Integrated Reporting - IR that presents financial and non-financial information through integrated thinking. An Integrated Reporting presents a hybrid situation because it includes financial information that is subjected to a mandatory audit, and non-financial information that can be assured in a voluntary basis. In this way, the inclusion of assurance information can be seen through a legitimation lens representing the organizations' effort to increase legitimacy. The motivation behind this paper is to discuss the assurance presented on Integrated Reporting. The research's objective is to provide an analysis on the differences between companies from different geographical origins related to the assurance provided on Integrated Reporting. The methodological approach is characterized by a qualitative study on the assurance included in Integrated Reporting. The empirical analysis is related to the analysis of the reports of 45 organizations. We find that the company's geographical origins implicate differences in the information disclosed related to assurance. The paper's contribution consists on new insights into the emergent field of assurance on Integrated Reporting with the increase of the understanding of the assurance report's characteristics, which are disclosed by companies from different geographical settings.
\end{abstract}

Keywords - Integrated Reporting, Legitimacy Theory, Sustainability Reporting, Sustainability Assurance, Integrated Reporting Assurance.

\section{INTRODUCTION}

Integrated Reporting has become more relevant as a tool for assessing corporate sustainability by investors [1]. An Integrated Reporting presents a hybrid situation because it includes financial information that is subjected to mandatory audit, and non-financial information that can be assured in a voluntary basis. In this way, the inclusion of assurance information can be seen through a legitimation lens representing the organizations effort to increase legitimacy. The increasing implementation of Integrated Reporting and the inherent need to ensure the compliance of the disclosed information, lead to the need for new standards for assurance reports. Therefore, it is necessary to develop audit standards that respond to these challenges [2], [3]. The inclusion of assurance reports on Integrated Reporting can increase the reliability of the information disclosed [2], [4]-[6].
Integrated Reporting and the assurance of sustainability information represent two recent trends related to non-financial reporting [7]. In particular, the study of assurance reported in Integrated Reporting is an emergent topic of growing relevance and yet to be developed [8], [9]. The International Integrated Reporting Council - IIRC - has only recently published studies on the subject [10]-[12]. This study motivation is in Assurance in Integrated Reporting in order to increase is reliability. This paper answer to calls for research in the area of assurance services in different geographical settings [13].

The purpose of this study is to verify if Integrated Reporting includes assurance reports and to provide an analysis on the differences between companies from different geographical origins related to the assurance provided on Integrated Reporting. The empirical work develops a study using data from the reports included in the "Integrated Reporting Examples Database" of the International Integrated Reporting Council, which covers 45 corporate reports from 2017. The analysis includes the information disclosed by the companies, financial audit and assurance information. The results show that the company's geographical origins implicate differences in the information disclosed related to assurance on the following aspects: the existence of disclosure of independent assurance, the origin of the assurance providers between audit firms and assurance independent providers, the opinion issued by the assurance providers and the inherent limitations, the existence of specific work developed in Assurance on Integrated Reporting and the different standards used by assurance practioners. This paper's contribution consists of new insights to the emergent field of assurance on Integrated Reporting with the increase in the understanding of the characteristics of companies from different geographical settings' assurance.

To address its aims, the paper is organized as follows. Section II provides a literature review related to Sustainability Report, Integrated Reporting and Assurance on Integrated Report. Section III develops a presentation of the findings with an explanation of the empirical work and a description of the results. Section IV continues with a discussion of the results. The final section draws conclusions and present an agenda for future research. 


\section{LITERATURE REVIEW}

\section{A. Sustainability Report}

As a way of responding to internal and external pressures, organizations need to manage their social and environmental responsibilities [14] and to demonstrate to society in general, and investors in particular, the adequacy of their behaviour in social and environmental aspects [15]. Sustainability reports consist of reporting the social, environmental and economic impacts caused by the action of organizations [16]. A sustainability strategy is the one that enables the organization to add value to investors while contributing to building a sustainable society [17]. To reinforce the topic's relevance, the European Union has issued a directive related to the dissemination of non-financial information and diversity, which was applicable in 2017 [18]. The 2014/95/EU Directive requires European listed companies, insurers and banks to include a social, environmental and diversity statements in their management report [19].

\section{B. Integrated Reporting}

In 2004 the beginning of "The Prince's Accounting for Sustainability Project" was promoted, which aimed to develop the dimension of sustainability in organizations. In 2009, the International Integrated Reporting Council was established, and the first conceptual framework for integrated reporting has emerged in 2013 [20]-[22].

Integrated Reporting consists of a concise communication on how an organization's strategy, in the context of its external environment, leads to the creation of value in the short, medium and long terms, using the six capitals with integrated thinking [22]. The fundamental concepts are value creation and the six capitals. The process of creating value consists of identifying how the organization uses its business model to select the elements to use, to process those elements and to obtain results. The Integrated Reporting takes an integrated view, with financial and non-financial capital together with integrated thinking. The six capitals on which this reporting model is based are: financial, productive, intellectual, human, social, and natural relationship.

\section{Assurance on Integrated Report}

In the last decades, an increase in the demand for independent assurance in other domains than the financial information audit has occurred. In particular, the demand for sustainability assurance, as well as the number of sustainability assurance providers have increased. [23]. Recent studies reveal that the assurance of sustainability information implicates a higher importance of this information and is associated with the growth of the perceived sustainability performance [7]. Integrated Reporting is a hybrid practice between financial reporting and sustainability reporting. In order to obtain a state of legitimacy, these two types of information must be reconciled. Legitimacy consists of a generalized perception that the action developed by an entity is appropriate, desirable and adequate in accordance with established social norms, values, beliefs, and definitions [24]. Organizations seek assurance reports as a way of achieving reputational benefits. This expected reliability and legitimacy leads to new questions such as: To what extent and at what level of analysis do information users expect reliable assurance reports?, What kind of opinion is issued (positive or negative)?, as part of the financial audit or in supplementary form [11]. Following this subject, the "International Integrated Reporting Council" developed initiatives and initiated a debate on the credibility and veracity of Integrated Reporting with emphasis on the development of independent assurance and subsequent emission of the independent reports [10], [12].

Assurance reports carry out the analysis of non-financial information that includes social and environmental information. These reports may have a positive or a negative opinion. In a positive opinion, the auditor analyses the evidence and expresses his opinion on its adequacy with the reality of the company. This type of opinion is usually attributed to the financial report (Eccles \& Saltzman, 2011). In a negative opinion, the auditor expresses his opinion through a statement that nothing has come to his attention that would lead him to suspect that the information is unreliable. This is a limited type of audit conclusion and is presented in respect to non-financial information (Gary et al., 2011; Reverte, 2015).

\section{FINDINGS}

\section{A. Description of the empirical work}

The empirical work aimed to determine whether the companies that present integrated reports, and which are included in the database of the International Integrated Reporting Council, include in the disclosed information an assurance report for non-financial information. Subsequently a characterization of the assurance reports by geographical origin was carried out.

The study involved the following phases: characterization of the organizations subject to analysis, determination of the frequency of submission of an assurance report, characterization of the type of opinion issued, characterization of the type of organizations providing the assurance service and determination of the standards used by the assurance providers.

\section{B. Results}

From the analysis of Figure 1 it is possible to conclude that from 45 companies, 27 present Assurance Reports on nonfinancial information. Between geographical origins, the most relevant difference is between Africa, with $76 \%$ of reports with assurance, while Europe only presents $41 \%$ of reports with assurance. From this information, we can conclude that Africa has a higher percentage of companies presenting assurance on non-financial information. 


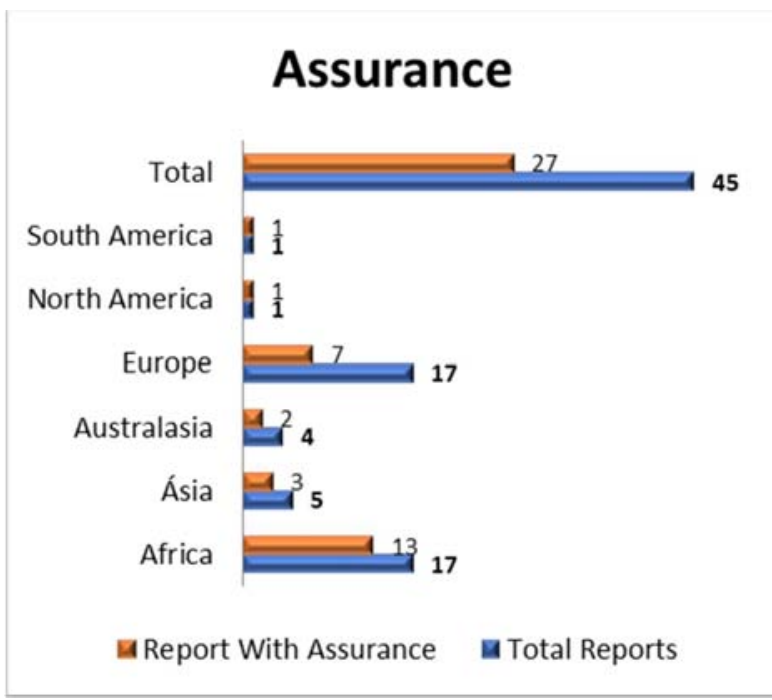

Figure 1. Reports with assurance

The assurance provider is divided in auditors, assurance providers and others. From the information shown in Figure 2, it is possible to conclude that the assurance providers are mainly the big four auditors with more significance in PwC and KPMG. The independent assurance providers are Independent and licensed providers of sustainability assurance services and are the following: DNV - Det Norske Veritas AS, ERM Southern Africa (Pty) Ltd, and Ibis ESG Assurance Proprietary Limited.

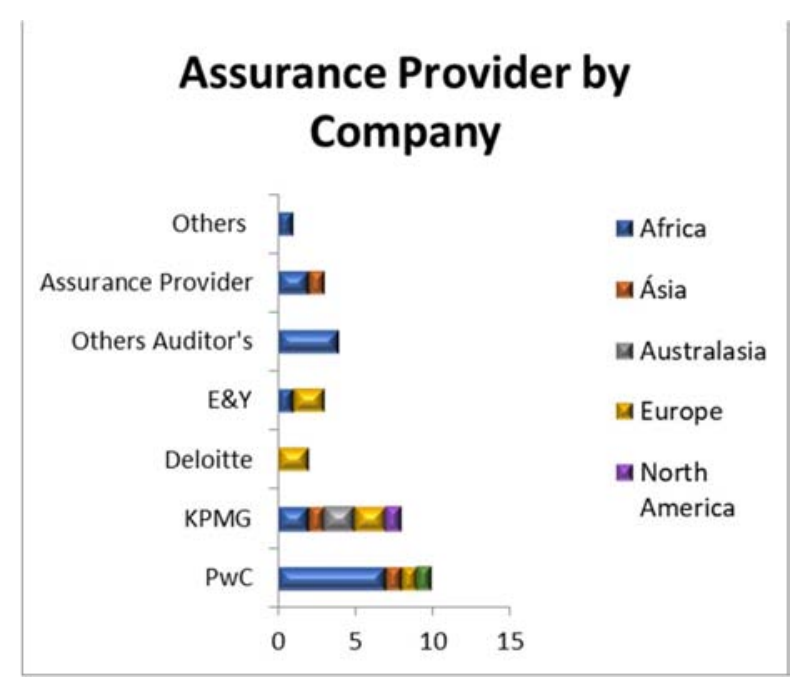

Figure 2. Assurance Provider by Company

By geographical origins, the results presented in figure 3 show that in Africa the most representative assurance provider is $\mathrm{PwC}$ followed by companies from the audit profession other than the big four. Furthermore, the independent assurance providers and KPMG are relevant in this region. In Europe, the assurance providers belong to the big four companies from the audit profession. In Asia the assurance providers are KPMG, $\mathrm{PwC}$ and an independent assurance provider. In North America the assurance provider is KPMG and in South America the assurance provider is $\mathrm{PwC}$.

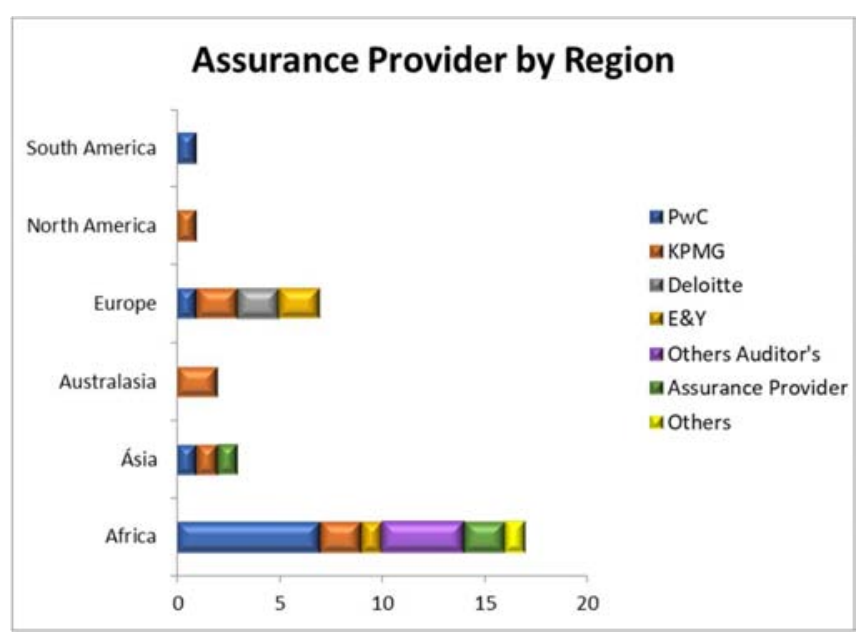

Figure 3. Assurance Provider by Region

Figure 4 presents the financial auditors by audit company. The most representative is KPMG followed by PwC. The results show that Deloitte and E\&Y are less significative and that some companies have other audit companies as financial auditors.

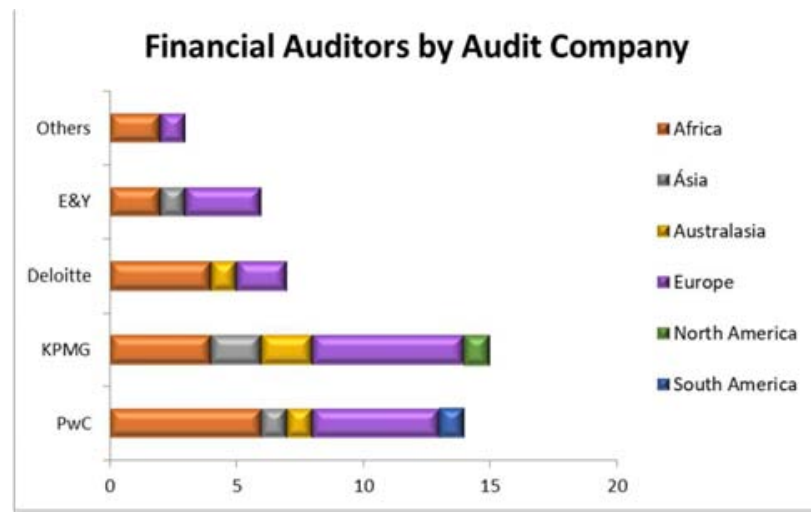

Figure 4. Financial Auditors by Audit Company

Figure 5 presents the Financial Auditors by geographical origins. In Africa the most representative is PwC followed by KPMG and in Europe the most representative is KPMG followed by PwC. One important conclusion is that most of the times the financial auditor is the same as the assurance provider. 


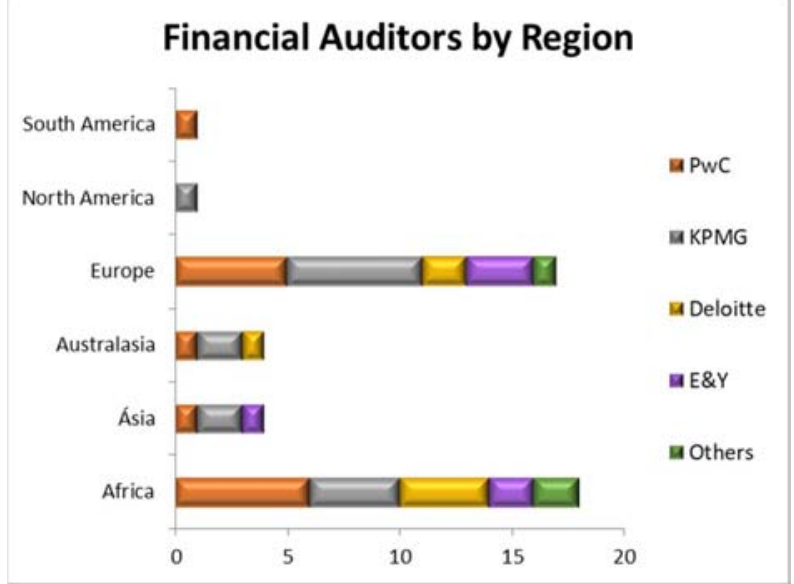

Figure 5. Financial Auditors by Region

Figure 6 presents the Level of Assurance. Assurance provided by financial auditors can be expressed in a positive and negative way. Based on ISAE 3000 there can be either a Limited Assurance Engagement that represents a moderate level of assurance and a Reasonable Assurance Engagement that represents a High level of assurance. If the assurance is provided by an independent assurance provider based on AA1000 AS, it can be either a Moderated Assurance that represents a moderate level on assurance or a Hight Level of Assurance.

Data shows that the most representative level of assurance expressed in the assurance reports is a Limited Assurance. Only few companies present a Reasonable Assurance.

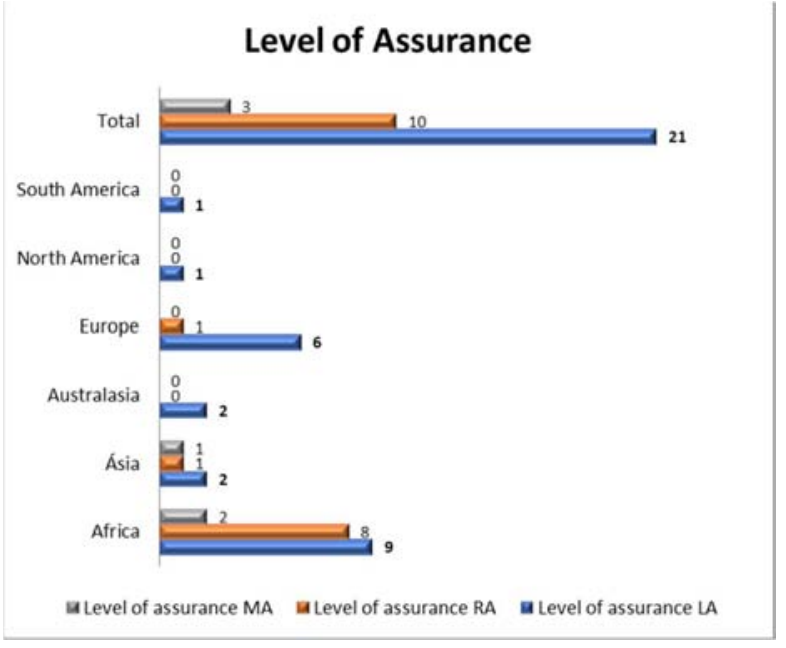

Figure 6. Level of Assurance

Figure 7 presents the Independent Assurance Standards used by the assurance providers.

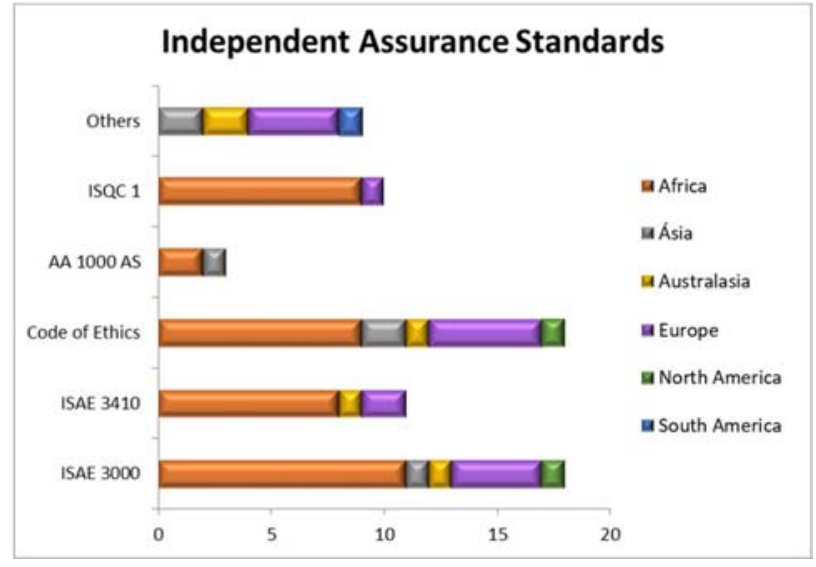

Figure 7. Independent Assurance Standards

The most used standard used by the assurance providers that belong to the audit profession is the International Standard for Assurance Engagements Other Than Audits or Reviews of Historical Financial Information (ISAE 3000) issued by the International Auditing and Assurance Standards Board (IAASB), and the International Standard on Assurance Engagements (ISAE 3410) Assurance Engagements on Greenhouse Gas (GHS) statements also issued by the IAASB.

Assurance providers use Codes of Ethics such as: IESBA Code of Ethics: Code of Ethics for Professional Accountants issued by the International Ethics Standard Board for Accountants; ICAEW Code of Ethics: issued by the Institute of Chartered Accountants in England and Wales; IRBA Code: Code of Professional Conduct for Registered Auditors issued by the Independent Regulatory Board for Auditors, South Africa. The IRBA Code is consistent with the International IESBA Code of Ethics; IFAC Code of Ethics: Code of Ethics for Professional Accountants issued by the International Federation of Accounts; APES 110: Code of Ethics for Professional Accountants issued by the Australian Professional and Ethical Standards Board; Code of Ethics issued by the Institute of Chartered Accountants of Sri Lanka; ACRA Code: Accounting and Corporate Regulatory Authority Code of Professional Conduct and Ethics for Public Accountants and Accounting Entities (Singapura); VGBA - Dutch Code of Ethics; Code of Ethics for Professional Accountants issued by the Council of International Standards of Ethics for Accountants, México.

Independent assurance providers use the AccountAbility's standard AA1000 Assurance Standard (AA1000AS). AA1000 consists on Standards used to demonstrate leadership and performance in accountability, responsibility and sustainability.

Assurance providers also use the International Standard on Quality Control (ISQC 1), the quality control for firms that perform audits and reviews of financial statements, and other assurance and related service engagements.

Other standards used to perform the assurance service are: 3810N Dutch Standards - Assurance Engagements relating to sustainability Reports (Dutch standard based on the ISAE 3000); ICMM - International Council of Mining and Metal's Assurance procedures; NBC T0 3000 Assurance engagements other than 
Audit and Review, issued by the Brazilian Federal Accounting Council (CFC); SLSAE 3000 Assurance Engagements Other Than Audits or Reviews of Historical Financial Information issued by the Institute of Chartered Accountants of Sri Lanka; Singapore Standard on Quality Control 1; SSAE 3000 Singapore Standard on Assurance Engagement 3000, Assurance Engagements Other Than Audits or Reviews of Historical Financial Information; Australian Standard on Quality Control 1; New Zealand Auditing and Assurance Standards: NZ ISAE 3000 International Standard for Assurance Engagements Other Than Audits or Reviews of Historical Financial Information, NZ Standard on Assurance Engagements ISAE 3100 Assurance Engagements on Compliance ; UK ISQC 1 - International Standard on Quality Control (United Kingdom); ISQC Italy 1 International Standard on Quality Control (Italy)"

\section{DISCUSSION}

The obtained results refer to 45 corporate reports from 2017 from companies in Europe, Africa, Australasia, Asia, North America and South America. Previous studies indicate that Europe (Spain) registered more sustainability reports than the United States, a result that is consistent with those obtained now [25]. In relation to the disclosure of assurance reports, the results indicate that $70 \%$ of the analysed companies voluntarily present Assurance Reports. Differences between different geographical settings were noted. Africa has a percentage of $76 \%$ of reports with independent assurance while Europe only registers the value of $41 \%$. To justify this difference, it is important to mention that listed companies from South Africa adopt Integrated Reporting in an "apply or explain basis" and that in this geographic area assurance is considered important for accountable governance [19]. Comparing the obtained results with previous studies, (Gomes, Eugénio, and Branco 2015) we have verified a consistency in the typology of the assurance providers as belonging to the audit profession, mainly the big four professional firms [23], [26], but while in Europe, South America, North America and Australasia assurance providers were totally from audit firms, in Africa and Asia they also come from assurance independent providers. It was noted that, most of the times, the assurance providers were the same as the financial audit company. This can be explained by the promotion made by audit companies of the use of a single assurance provider for the financial audit and the non-financial assurance services [13].

One important feature related to assurance is the opinion of the assurance providers. It was found that it consists mostly of a limited opinion [23], [26]. With the analysis of the assurance reports, it was also possible to verify that the opinion expressed is solely for the internal use of the organization subjected to assurance. In fact, there is a limitation on the use of the assurance reports, this limitation is expressed as being related to the nature of non-financial information that has a more difficult verification and confirmation. On the other hand, this limitation, expressed in the assurance report, also limits the use of this certification by entities external to the company and by investors. It was also noted that managers decide what information to assure and that this can reduce the independence of assurance providers [19]. In the analysis of the work performed by the assurance providers, it was possible to verify that the specific aspects of the Integrated Reporting, such as the six capitals and the value creation process, are not subject to certification. In this way, the developed certification process for the Integrated Reporting is similar to the process developed for the sustainability reports. The standards used by assurance practitioners are directly related to the type of assurance provider. While assurers from the audit profession prefer to use ISAE 3000, independent assurers use AccountAbility standard AA1000AS [13].

The limitations of the paper are related to the analysis of a limited number of organizations and the reference to one year of analysis, considering that the study is based in a small sample, there is a need for further research.

\section{CONCLUSIONS}

This study contributes to the emerging Assurance on Integrated Reporting literature by assessing assurance reports and the difference existing among companies from different geographical areas. This paper intends to raise questions about the relevance of the inclusion of assurance reports in the integrated report and the contribution to the legitimacy of the disclosed information. Integrated Reporting is a recent reporting model, which aggregates information traditionally presented in different reports. This new report creates challenges as to how information can be gauged and presented to users as credible information. At this level of legitimacy, it is relevant the audit of financial information and the assurance of non-financial information. With the analysis done in this paper, it was possible to conclude that organizations are including in the disclosed information, in a voluntarily basis, assurance reports with differences related to the geographical origin of the companies. Regarding the type of assurance report, it was possible to verify that the expressed opinion is most of the times a limited opinion, with the statement that the opinion is only for internal use of the organization subject to assurance. It was also verified that the work done by the assurance providers in an Integrated Reporting is similar to the work developed in sustainability reports, and there is no specific work associated with the particularities of the Integrated Reporting.

The subject of assurance in Integrated Reporting is an emergent topic and needs to be further analysed and debated. As future work, the mechanisms used by organizations to increase the credibility of the information contained in the Integrated Reports, of which assurance reports are a part, can be addressed. The work developed in this article should be complemented with a longitudinal study using more companies and more years that can bring conclusions on the evolution already registered. Considering that the practice of Integrated Reporting is recent, it is necessary to monitor its evolution with the evolution of assurance and information audit work. The study of the relationship between the benefits and costs of reliability assurance work should be developed. The providers of the assurance and auditing services should develop higher understanding on the Integrated Reporting, such as the process of how organizations create value, the six capitals and the development of integrated thinking. The study on the 
development of new auditing standards and assurance work should also be addressed, allowing for greater integration between the expectations of the organizations' stakeholders and the auditors and organizations providing assurance services.

\section{ACKNOWLEDGMENT}

We would like to thank for the financial support of FCT Foundation for Science and Technology (Portugal), "national funding through research Grant" (UID/SOC/04521/2013).

\section{REFERENCES}

[1] P. Druckman, "Integrated Reporting: A New Governanee Tool,"

$$
\text { Corp. Board, pp. 6-11, } 2014 .
$$

[2] C. de Villiers, L. Rinaldi, and J. Unerman, "Integrated Reporting: Insights, gaps and an agenda for future research," Account. Audit.

$$
\text { Account. J., pp. 1-47, } 2014 .
$$

[3] M. A. Rodrigues, A. I. Morais, and J. V. da Cunha, "Integrated Reporting $<\mathrm{IR}>$ : O novo paradigma em Corporate Reporting," Rev. da Ordem dos Revisores Of. Contas, no. 35, p. PP 34, 41, 2016.

[4] R. G. Eccles, M. P. Krzus, J. Rogers, and G. Serafeim, “The Need for Sector-Specific Materiality and Sustainability Reporting Standards," Appl. Corp. Financ., vol. 24, no. 2, pp. 65-71, 2012.

[5] C. M. Gary, A. Fagerström, and L. G. Hassel, "Accounting for Sustainability: What Next? a Research Agenda," Ann. Fac. Econ.,

$$
\text { pp. 97-111, } 2011 .
$$

[6] G. Pflugrath, P. Roebuck, and R. Simnett, "Impact of assurance and assurer's professional affiliation on financial analysts' assessment of credibility of corporate social responsibility information," Auditing, vol. 30, no. 3, pp. 239-254, 2011.

[7] D. Reimsbach, R. Hahn, and A. Gürtürk, "Integrated Reporting and Assurance of Sustainability Information: An Experimental Study on Professional Investors' Information Processing," Eur. Account. Rev., vol. 27, no. 3, pp. 559-581, May 2018.

[8] C. A. Adams, "The International Integrated Reporting Council: A call to action," Crit. Perspect. Account., vol. 27, pp. 23-28, Mar.

$$
2015 .
$$

[9] J. Dumay, C. Bernardi, J. Guthrie, and P. Demartini, "Integrated reporting: A structured literature review," Account. Forum, vol. 40, no. 3, pp. 166-185, Sep. 2016.

[10] IIRC, “Assurance on IR: An Introduction to the Discussion." pp. 19, 2014. action," no. July. 2015.

[13] M. B. Farooq and C. de Villiers, "The shaping of sustainability assurance through the competition between accounting and nonaccounting providers," Accounting, Audit. Account. J., vol. 32, no.

$$
\text { 1, pp. 307-336, } 2019 .
$$

[14] L. Klovienè and M. T. Speziale, "Sustainability Reporting as a Challenge for Performance Measurement: Literature Review,"

$$
\text { Econ. Bus., vol. 26, p. 44, } 2014 .
$$

[15] M. A. Odriozola, J. A. C. Saánchez, and I. Á. Etxeberria, "Divulgación de información sobre corrupción: empresas del ibex 35*,"Rev. Contab. Account. Rev., vol. 15, pp. 59-90, 2012.

[16] W. Stubbs and C. Higgins, "Integrated Reporting and internal mechanisms of change," Accounting, Audit. Account. J., vol. 27, no. 7, pp. 1068-1089, Aug. 2014.

[17] R. G. Eccles and G. Serafeim, "A table of two stories: Sustainability and the Quarterly Earnings Call," Appl. Corp. Financ., vol. 25, no.

$$
\text { 3, pp. 8-19, } 2013 .
$$

[18] European Parliament, "Directive 2014/95/EU of the European Parliament and of the Council of 22 October 2014 amending Directive 2013/34/EU as regards disclosure of non-financial and diversity information by certain large undertaking and groups," Off. J. Eur. Union, vol. 2014, no. April, pp. 1-9, 2014.

[19] M. Corrado, P. Demartini, and J. Dumay, "Assurance on Integrated Reporting: A Critical Perspective," in Springer International Publishing, 2019, pp. 199-217.

[20] A. Fried, M. P. Holtzman, and D. Mest, "IR the new annual Report for the 21st century,” Financ. Exec., vol. Fall 2014, pp. 24-31, 2014.

[21] International Integrated Reporting Council (IIRC), “A Estrutura Internacional para Relato Integrado," 2013.

[22] International Integrated Reporting Council (IIRC), "The International IR framework," p. 37, 2013.

[23] M. Canning, B. O’Dwyer, and G. Georgakopoulos, "Processes of auditability in sustainability assurance-the case of materiality construction," Account. Bus. Res., vol. 49, no. 1, pp. 1-27, 2019.

[24] M. C. Suchman, "Managing Legitimacy: Strategic and Institutional Approaches," Acad. Manag. Rev., vol. 20, no. 3, p. 571, Jul. 1995.

[25] R. G. Eccles, M. P. Krzus, and L. a. Watson, "Integrated Reporting Requires Integrated Assurance," QFinance, pp. 1-14, 2010.

[26] M. A. B. Rodrigues, A. I. Morais, and C. Ribeiro, "Assurance on integrated reporting <IR >," in 2017 12th Iberian Conference on Information Systems and Technologies (CISTI), 2017, pp. 1-6. 